\title{
AMBIENT OZONE AND EMERGENCY DEPARTMENT VISITS DUE TO LOWER RESPIRATORY CONDITION
}

TERMEH KOUSHA ${ }^{1}$ and BRIAN H. ROWE ${ }^{2}$

\author{
${ }^{1}$ University of Ottawa, Ottawa, Canada \\ Department of Mathematics and Statistics \\ ${ }^{2}$ University of Alberta, Edmonton, AB, Canada \\ Department of Emergency Medicine and School of Public Health
}

\begin{abstract}
Objectives: Ambient ozone $\left(\mathrm{O}_{3}\right)$ exposure is associated with a variety of health conditions. The objective of this study was to examine the effect of increased daily concentrations of ozone on emergency department (ED) visits due to lower respiratory diseases (LRD), such as acute or chronic bronchitis, in Edmonton, Canada. Materials and Methods: Data concerning 10 years (1992-2002) were obtained from 5 Edmonton hospital Emergency Departments. Odds ratios (ORs) for ED visits associated with the increased ozone levels were calculated employing a case-crossover technique with a time-stratified strategy to define controls. In the constructed conditional logistic regression models, adjustments were made for daily number of influenza ED visits and weather variables using natural splines. ORs and their $95 \%$ confidence intervals (95\% CI) were reported in relation to an increase in the interquartile range $(\mathrm{IQR}=17.9 \mathrm{ppb})$ of the ground-level ozone. Results: Overall, 48252 ED visits due to LRD were identified, of which $53 \%$ were made by males. The presentations peaked in December $(12 \%)$ and February (11.7\%) and were the lowest in August (5.6\%). Positive and statistically significant results were obtained for acute bronchitis: for same day $(\mathrm{OR}=1.09,95 \% \mathrm{CI}: 1.05-1.13$, lag 0$)$ and for lag 2, lag 3-7 and 9 days; for chronic bronchitis: for lag 6, 7, and lag 9 days (OR = 1.11, 95\% CI: 1.05-1.18, lag 9). For all ED visits for LRD, lag 0, lag 1, and lag 3-9 days showed positive and statistically significant associations $(\mathrm{OR}=1.06,95 \% \mathrm{CI}: 1.03-1.09$, lag 0$)$. Conclusions: These findings support the hypothesis concerning positive associations between ozone and the ED visits due to LRD.
\end{abstract}

Key words:

Bronchitis, Case-crossover, Ozone, Lower respiratory diseases

\section{INTRODUCTION}

Lower respiratory symptoms and conditions are defined as lower respiratory tract infections such as pneumonia, but can be also applied to other types of infections including lung abscess and acute bronchitis. Symptoms of lower respiratory tract conditions, such as shortness of breath, wheeze, dyspnea and cough are also common emergency department (ED) presenting complaints. While these problems are present throughout the whole year, in many high latitude Northern and Southern hemispheric countries they predominate in cold seasons. There is a variety of causes for these conditions including viral and bacterial infections, cigarette smoking and second hand exposure, non-compliance with chronic medications as well as poor air quality.

In this study, we have considered ED visits due to lower respiratory diseases (LRD). We have investigated the association between the ambient ground-level ozone $\left(\mathrm{O}_{3}\right)$

The research is supported by a Tier I Canada Research Chair in Evidence-based Emergency Medicine from the Canadian Institutes of Health Research (CIHR) through the Government of Canada (Ottawa, Ontario).

Received: October 28, 2013. Accepted: December 16, 2013.

Corresponding author: T. Kousha, University of Ottawa, 585 King Edward, Ottawa, ON, K1N 6N5, Canada (e-mail: tkousha@uottawa.ca). 
exposure and ED presentations diagnosed as LRDs, including acute/chronic bronchitis and chronic airway obstruction (See Table 1 for a detailed list of the classified health endpoints). Ambient ozone is recognized to adversely affect respiratory health. Ozone is absorbed by both upper and lower respiratory tract, and is a powerful oxidant that can damage respiratory tract, causing inflammation and irritation. Previous work has identified ozone levels as being associated with a variety of ED respiratory [1-4] and non-respiratory presentations such as otitis media [5], conjunctivitis, skin conditions [6] and cellulitis [7,8].

To investigate potential correlations between the ground level ozone concentration and these lower respiratory conditions, we used a comprehensive ED database from Edmonton, Canada. A case-crossover (CC) design [9] was applied for this type of data. Daily counts of ED visits due to LRD were used to represent considered health outcomes. These daily counts were analyzed as a number of separate individual events on a specific day. The ground level ozone was represented as the highest daily maximum 8-hour average of ozone concentrations. Weather variables, i.e. temperature and relative humidity were expressed as daily mean values.

\section{MATERIALS AND METHODS}

The data on ED visits were supplied by the former Capital Health (now called Alberta Health Services (AHS) - Edmonton Zone) for all the 5 major acute care hospitals in the Edmonton area. Edmonton has an academic-focused health care system and is a part of one of the largest integrated health regions in Canada. The system provides complete health services to approximately 1 million residents. The sites are staffed with full-time Emergency Physicians. Each site deals with approximately 50000 visits

Table 1. Lower respiratory disease classification used in the study of ED visits in Edmonton

\begin{tabular}{lrr}
\hline \multicolumn{1}{c}{ Description of the diagnosed ED visits } & ICD-9 code & Counts \\
\hline Acute bronchitis & 466.00 & 12864 \\
Acute bronchiolitis & 466.10 & 3665 \\
Acute bronchiolitis due to respiratory syncytial virus & 466.11 & 1315 \\
Acute bronchiolitis due to other infectious organisms & 466.19 & 3888 \\
Bronchitis not specific acute/chronic & 490.00 & 10098 \\
Simple chronic bronchitis & 491.00 & 125 \\
Mucopurulent chronic bronchitis & 491.10 & 1 \\
Obstructive chronic bronchitis without exacerbation & 491.20 & 270 \\
Obstructive chronic with (acute) exacerbation & 491.21 & 5614 \\
Other chronic bronchitis & 491.80 & 14 \\
Unspecified chronic bronchitis & 491.90 & 137 \\
Emphysematous bleb & 492.00 & 15 \\
Other emphysema & 492.80 & 904 \\
Bronchiectasis & 494.00 & 400 \\
Chronic airway obstruction, not elsewhere classified & 496.00 & 8942 \\
Total & & 48252 \\
\hline
\end{tabular}

All descriptions are original from the used database. An ICD code identifies cases. 
annually; teaching medical students, interns and residents are also common.

The sample considered in this study were the patients served by these 5 hospitals in Edmonton, between April 1, 1992 and March 31, 2002. Almost 3 million ED records were identified in the database. The International Classification of Disease (ICD) 9th Revision (ICD-9) codes (World Health Organization, 1997) were applied to identify the cases classified as LRD, among them ICD-9 groups 466 (acute bronchitis) and 490 (chronic bronchitis). The analysis was performed separately for gender (all, males, females) and for the following strata: all ages, older than 65 years of age $(>65)$, younger than 19 years of age (0-18), older than 18 years of age (19-19+), warm period (April-September), cold period (October-March), and separately for the 2 subgroups of LRD (ICD-9: 466 and ICD-9: 490).

We have also retrieved and tabulated the daily number of visits due to influenza (ICD-9: 487.0, 487.1, 487.8; with 108, 12 986, and 2171 number of cases, respectively) to adjust for the potential confounding impact of the seasonal viral respiratory epidemic period.

Environment Canada's weather archive [10], supplied data for selected weather variables that were recorded hourly. Only 2 meteorological variables were used: ambient temperature (dry bulb) and relative humidity. The daily mean as an average of hourly readings (an average of 24 measurements) was used to represent daily values of these weather parameters. In the final models, the weather variables were used in a spline form as confounders. Natural cubic splines with 3 degrees of freedom were constructed.

The data on the ambient ground-level ozone were supplied by Environment Canada [11]. We acquired ozone levels measured only at the monitoring stations in Edmonton. For ozone measurements, the correlation between ozone levels for the 3 monitoring stations (northwest $-\mathrm{N}$, central $-\mathrm{C}$, and east $-\mathrm{E}$ ) were as follows:
E-N: $0.85 ; \mathrm{E}-\mathrm{C}$ : $0.89 ; \mathrm{N}-\mathrm{C}: 0.88$, based on 3.552 daily averages.

Maximum 8-hour average concentrations were used to represent the ozone exposure. The daily maximum was defined as the highest of the 24 possible 8-hour averages. A valid day measurement was defined as the one with at least 75\% (18 and more averages up to 24) of the possible 8-hour averages in the day.

The study used a case-crossover (CC) design, which is an adaptation of the case-control methodology employed elsewhere [9]. By definition, in the case-crossover technique the cases act as their own controls on a set of predefined control days proximate to the time they become cases. A time-stratified approach to determine referent control periods was widely adopted as it has been shown to produce unbiased conditional logistic regression estimates [12]. In the design, the controls are matched to the case periods by the day of the week for the case period (usually day), the control periods are determined as other days in the same month and year. This strategy was used here, thus, 3 or 4 controls were present for each case, depending on the day of the week when the case occurred and the number of days in the month. All statistical analyses were executed with SAS, using the procedure PHREG to realize the conditional logistic regression models.

A p-value less than 0.05 ( $p \leq 0.05)$ was considered statistically significant in all the presented statistical results. The results were reported as odds ratios (ORs) and their corresponding $95 \%$ confidence intervals (CI). The values of ORs were reported for an increase in the concentration represented as the interquartile range $(\mathrm{IQR}=75-25$ th values of percentiles, IQR $=17.9 \mathrm{ppb}$ ) of the ozone level. Since daily temperature and relative humidity may also affect acute outcomes of lower respiratory illness, we adjusted for these 2 variables. Temperature and relative humidity were used in a form of natural splines with the 3 degrees of freedom. All components, ozone and 
meteorological factors, in the constructed models were lagged by the same number of days, from 0 to 9 days.

For some health conditions, considered as a sub-group of lower respiratory disease, we performed our analysis separately: 466 (acute bronchitis) and 490 (chronic bronchitis). In the case of our logistic regression models we have also adjusted for the confounding impact of daily ED visits due to influenza.

\section{RESULTS}

Table 1 provides counts of ED visits due to lower respiratory conditions identified by ICD-9 codes and considered in this study as LRDs. The table includes original short descriptions of the diagnosed visits. Figure 1 shows the number of visits by sex and age (in years). The frequency of ED visits in the case of patients of 86 years of age and older ( $>86$ ) is represented by 1 point, which shows summarized frequencies for seniors. The overall number of visits was 48252 (males $=25$ 418, 53\%; females $=22834,47 \%$ ). The volume of visits varied from a low $5.6 \%$ in July to a high $12 \%$ in December. The values were expressed in relation to the total number of diagnosed visits considered in the study.

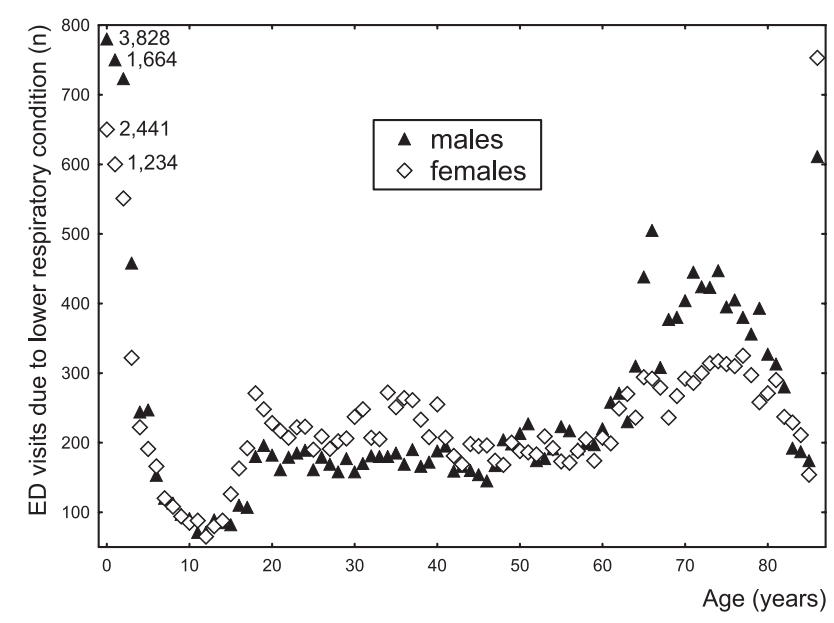

Fig. 1. Frequency of ED visits due to lower respiratory diseases by age and sex in 5 Emergency Departments in Edmonton, Canada (1992-2002)
The ozone values (daily averages from the 3 fixed monitors, each station had 24 hourly measurements and at least 1 station worked) were available during 3652 days and had the mean value of 18.6 ( $\mathrm{ppb}$ ), with standard deviation of 9.3, median value $=17.8, \mathrm{IQR}=14.0$ for daily mean, and IQR $=17.9$ for a maximum $8 \mathrm{~h}$ average ozone. Weather data obtained from the Environment Canada's weather archive had the following corresponding values for temperature of $3.9\left(^{\circ} \mathrm{C}\right), 11.9,5.4, \mathrm{IQR}=17.9$, and for relative humidity of $66(\%), 13.6,66.1, \mathrm{IQR}=18.5$, respectively.

The main results (estimated odds ratios) are displayed on 4 figures. These figures show the values of ORs and their 95\% CIs in numerical and graphical (line bars) forms. The results are reported for IQR $=17.9 \mathrm{ppb}$. The results were calculated for all, male and female patients with ozone exposure lagged by (same day) 0, 1, 2 up to 9 days in relation to the case day. Figure 2 represents values for all the ED visits due to lower respiratory conditions ( $\mathrm{N}=48252$ ) stratified by sex (all, males, and females). The left side of the figure shows the results for all ages and the right part for the patients older than 65 years of age $(>65)$. The results for 2 age groups - not older than 19 years of age (0-18), not younger than 18 years of age (19-19+) - are shown on Figure 3. Figure 4 provides the values of ORs and their $95 \%$ CIs for 2 strata: warm period (April-September) and cold period (October-March). Figure 5 illustrates the results for the ED visits due to acute bronchitis (ICD-9: 460, left part of the figure) and to chronic bronchitis (ICD-9: 490), right part of the figure.

The following patterns were noted for ozone and ED visits due to lower respiratory diseases. For all the patients positive and statistically significant results were obtained for ozone exposure lagged by 0,1 , and 3 to 9 days. For the male patients estimated ORs were significant for lags 0, 1, 3, 4, 7 and 9 days. For the female patients the ORs estimated for lag 0 and lags 4 up to 9 days had significant values. We observed association for older males $(>65)$ for lag 1 and lag 3 . 


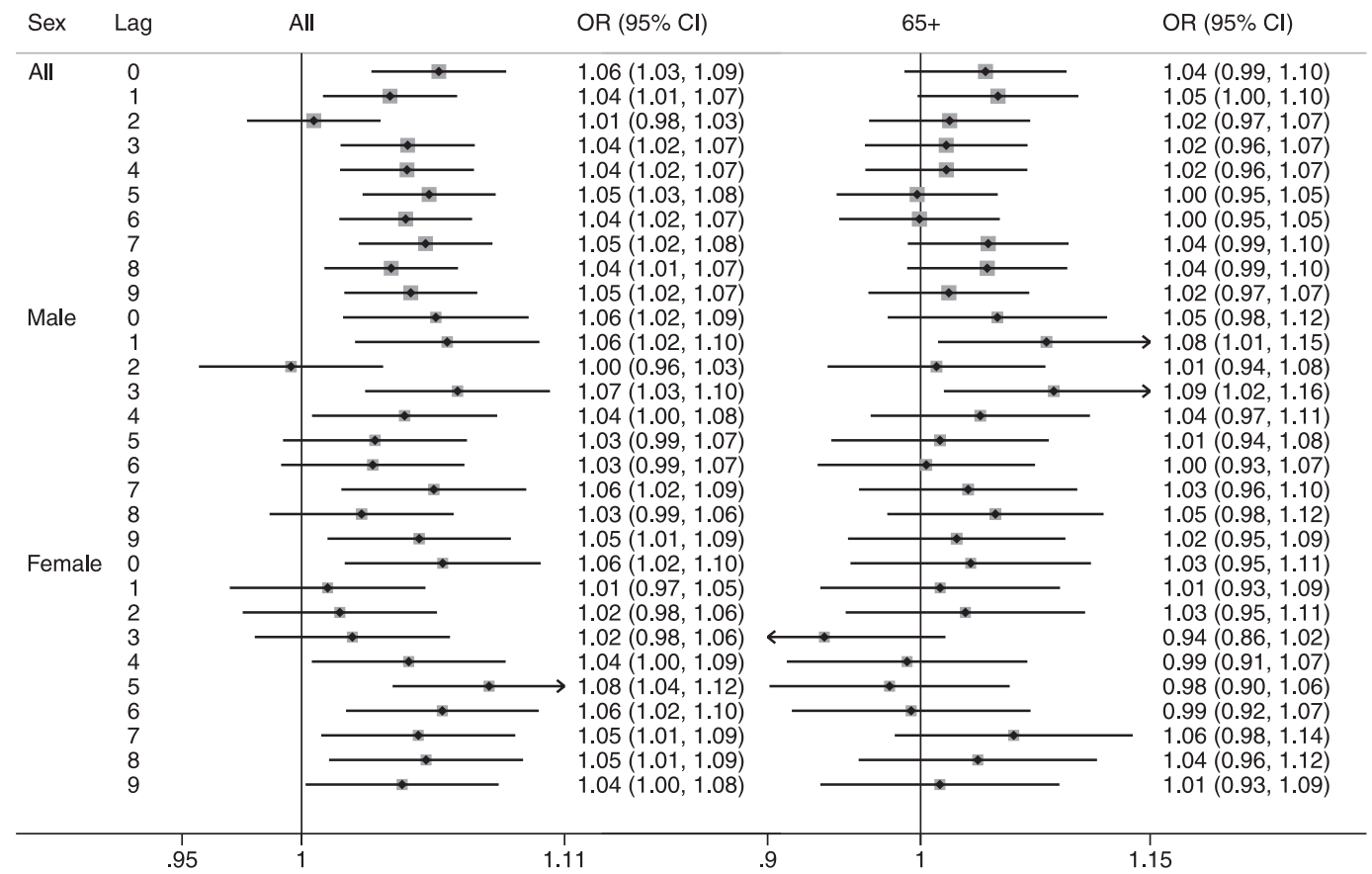

OR - odd ratios; CI - confidence intervals.

Interquartile range: $17.9 \mathrm{ppb}$.

Fig. 2. Patients of all ages and patients older than 65 years of age

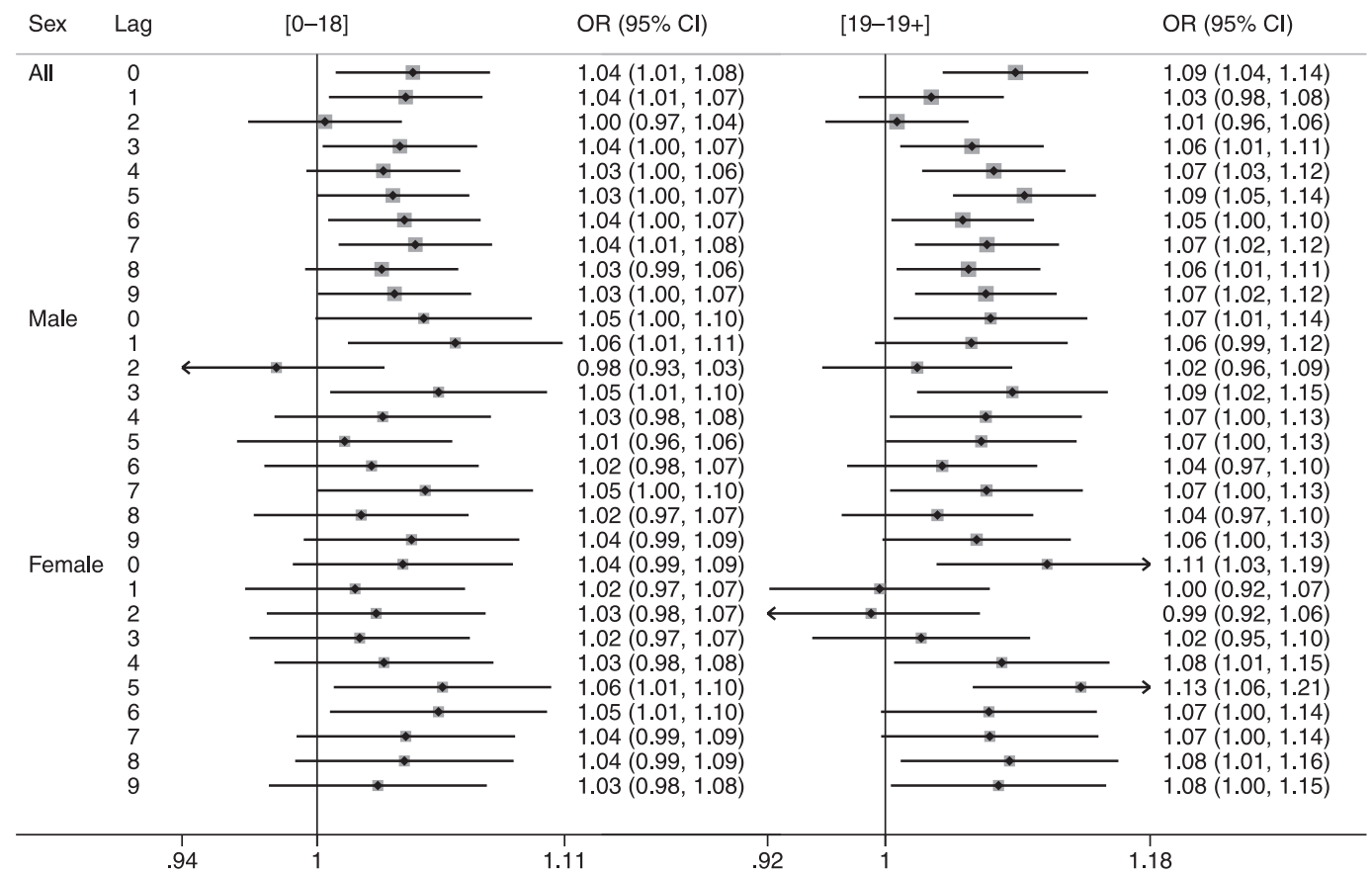

Abbreviations as in Figure 2.

Fig. 3. Two age groups: $0-18$ and $19-19+$ 


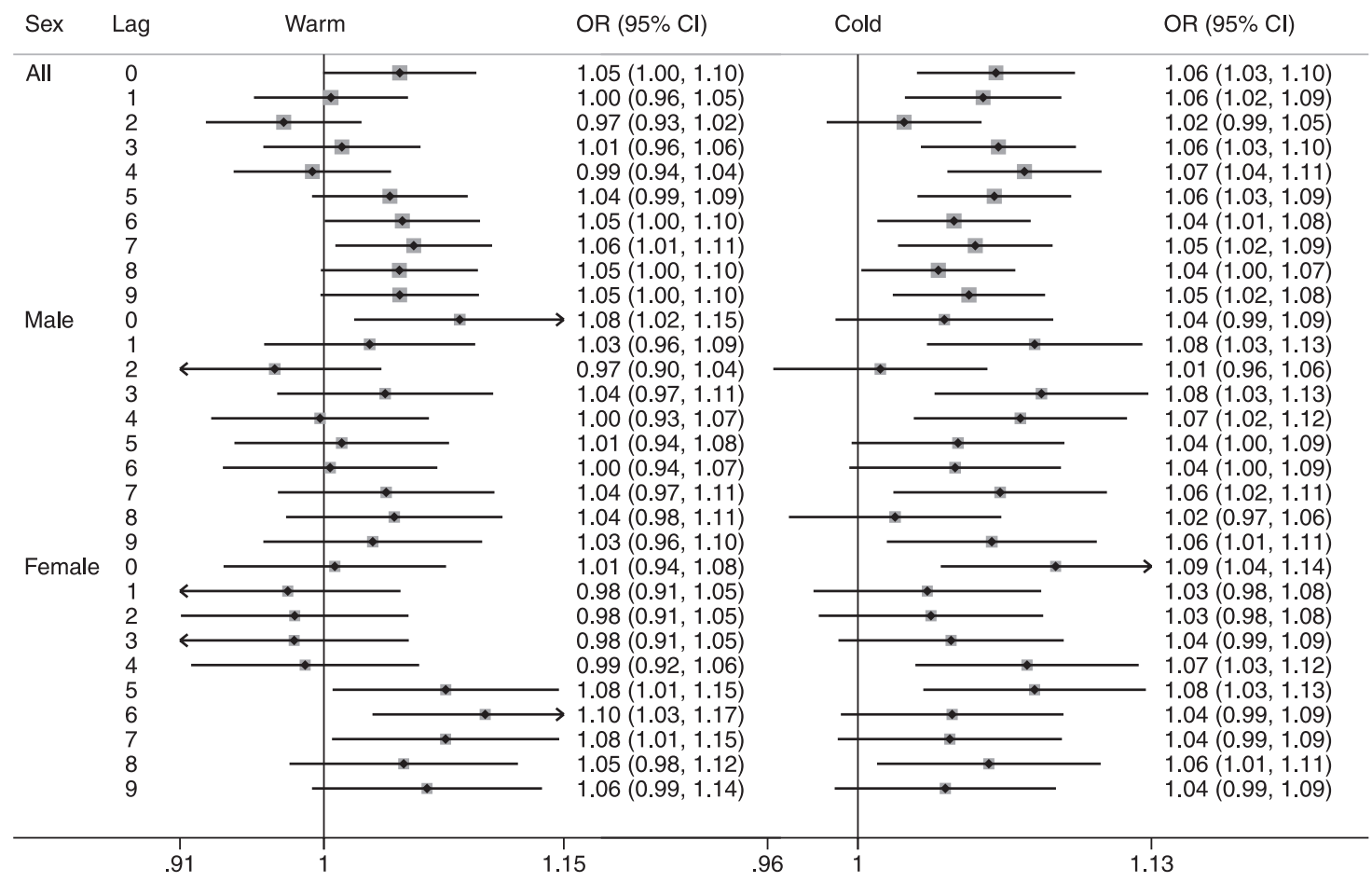

Abbreviations as in Figure 2.

Fig. 4. Two periods: warm months and cold months

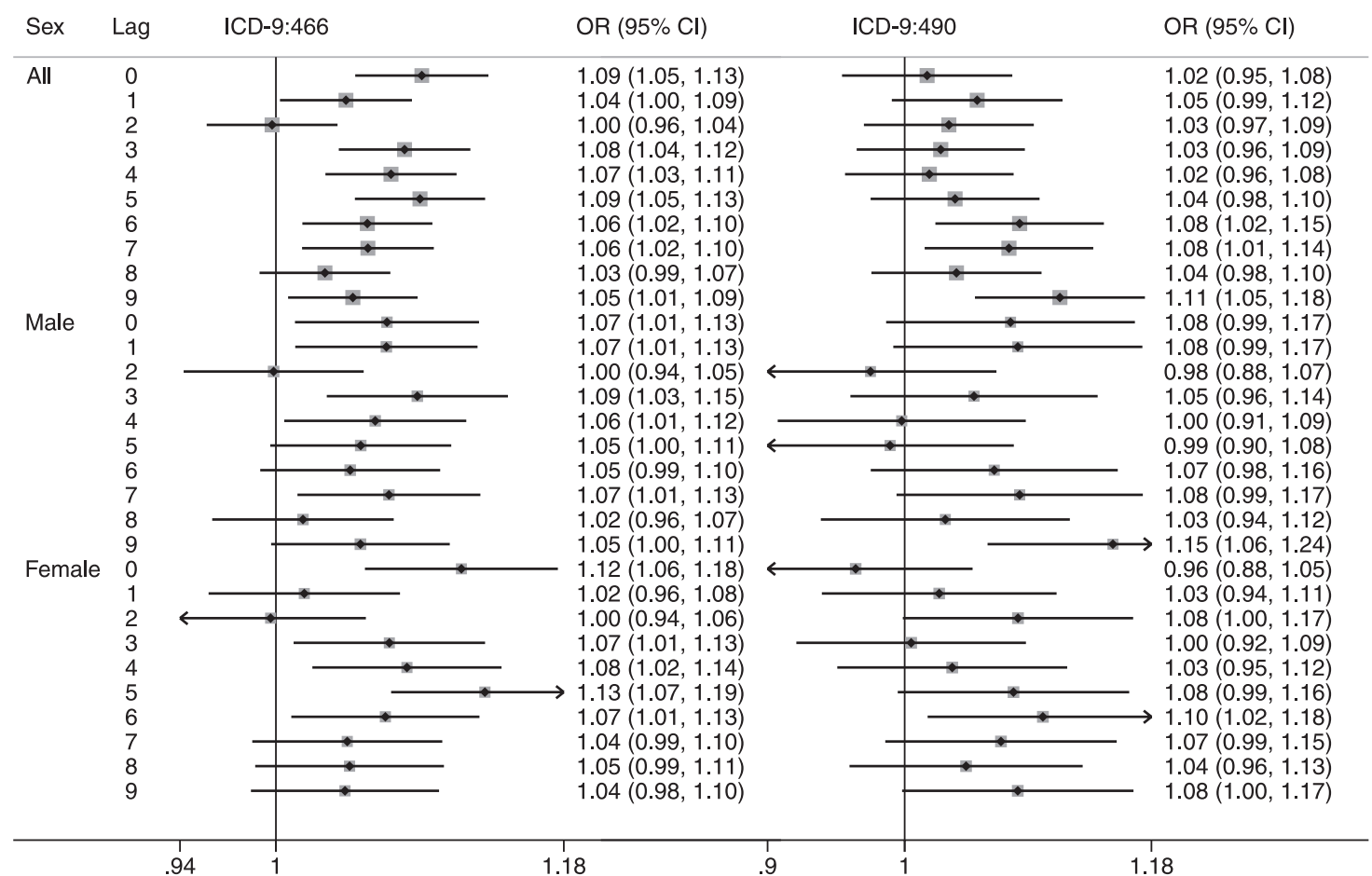

Fig. 5. Two ICD-9 groups $(466,490)$ 
Figure 3 indicates that the younger patients (the age group [0-18]), are more affected by recent exposure in relation to the day of ED visit. For both age groups we have also seen the effect on the same day of (lag 0 ) exposure. Figure 4 indicates that a larger number of positive effects was detected in the cold period in comparison to the warm period. Figure 5 indicates that more recent exposures had stronger associations with the ED visits due to acute bronchitis than to chronic bronchitis.

\section{DISCUSSION AND CONCLUSIONS}

Using a relatively large administrative database from 1 integrated geographic area in Western Canada (Alberta) linked to the reliable and valid Environment Canada data, we explored the association between the ozone levels and lower respiratory presentations to EDs in a northern Canadian region over a 10 -year period. Significant shortterm effects were observed for the ambient ground level ozone exposures on daily ED visits due to lower respiratory diseases. Ambient air pollutant affects patients differently depending on sex and the time of exposure (in terms of lagged days) resulting in different health conditions.

The number of visits due to bronchitis is bimodal: it peaks in early childhood and then again in older age. The early childhood peak probably represents a misdiagnosis. For example, "bronchitis" is not a disease of children or nonsmokers; however, asthma and bronchiolitis are. Since many children in early years with wheezing conditions receive a multitude of other diagnoses, the misclassification is not surprising. In addition, the second peak in older adults is probably a consequence of COPD, and men have more presentations than women. COPD is a rising cause of morbidity and mortality in many countries $[13,14]$.

There are several known and common causes of lower respiratory illnesses. Among them there are: viral and bacterial infections, cigarette smoke exposure (both primary and secondary) and poor air quality. This study indicates that poor air quality, in the form of higher levels of ozone, may contribute to bronchitis exacerbations that require ED visits. Ozone may induce morphological and biochemical effects in nasal and respiratory airways $[15,16]$. Airborne infectious, allergic and air pollution agents are among the most common inflammatory factors and ozone is among them.

Few published studies have examined the effect of air pollution on the lower respiratory conditions. As mentioned previously, we followed the methods of a similar study [3], by attempting to use similar disease categories and health outcomes. In another study [4], the authors obtained data on 4 million ED visits from 31 hospitals in Atlanta. They assessed visits due to asthma, chronic obstructive pulmonary disease, lower respiratory infection and pneumonia in relation to air pollutants using Poisson generalized estimating equations. As those authors stated, the results of their study contribute to the evidence of an association of several correlated gaseous and particulate pollutants, including $\mathrm{O}_{3}, \mathrm{NO}_{2}, \mathrm{CO}$, particulate matter $(\mathrm{PM})$, and organic carbon, with specific respiratory conditions [4]. Using the same Edmonton data, an association between asthma and the increased levels of $\mathrm{O}_{3}$ and PM has been identified previously [17]. In addition, ozone (lag 2 days) was most consistently associated with respiratory, but not cardiac, ED presentations [18].

In the presented study, we attempted to identify sex and time-lagged exposure for which ozone is correlated to lower respiratory conditions. Overall, our findings differ from the Atlanta study in 2 important ways. First, Edmonton and Atlanta have contrasting climates. Edmonton has a longer and more severe cold winter period and a shorter, less extreme and dryer summer period. In addition, Edmonton has a high proportion of sunny days, relatively dry climate and exposure to oil refineries in the surrounding communities that may influence the quality of air. Second, we have recruited a more homogenous population than the Atlanta and other Edmonton cohorts. 
In the literature there are several other studies that support these results. For example, using the same dataset we have explored the association between ozone levels and $0-3$ day lags in ED presentations due to otitis media. Otitis media is often a consequence of upper respiratory infections and is considered as a type of upper respiratory illness. There is also evidence of an association between ozone level and respiratory conditions such as asthma and pneumonia $[19,20]$. Finally, there is also evidence of an association between ozone level and skin conditions [6] and cellulitis [7,8]. These findings are not surprising since skin and respiratory tract are the main organs in direct contact with ambient ozone.

The casual associations could not be established using such a study design. The case-crossover methodology applied in our study, in which each patient serves as his or her own control, reduces or eliminates the confounding effects. Confounding might still be possible with timevarying characteristics.

The limitations of this study are typical of this type of research. They include the adequacy of the model and impact of measurement error in the exposure and outcome variables. The fixed-site monitoring sites available in Edmonton provide daily pollution exposures of ambient air pollution and are applied to represent average population exposure. The fixed site monitors do not fully reflect variation in exposure among individuals; however, alternatives are not readily available. The individual data on potentially important effect modifiers such as medication use, smoking status, socio-economic status, race and other medical co-morbidities were not available from this database. We have conducted numerous hypothesis tests, increasing the risk of false positive results; however, we have observed trends or similar statistical results for different health conditions categorized as lower respiratory conditions. Another study using the same ED data and statistical method and considering all respiratory conditions (ICD-9: 459-460,
$\mathrm{N}=292285$ ) as health endpoints, obtained positive and statistically significant associations with ozone for each lag [21-23].

Many episodes of lower respiratory conditions do not result in an ED visit, thus our findings are not generalizable to all such episodes. These data would, however, reflect the more severe LRD cases. It is possible that high ozone levels are correlated with sunny weather, when persons spend more time outside. This, in turn, is associated with them being exposed to other environmental factors that may also influence health. However, majority of the presentations were in the winter months.

The ground level ozone is formed when $\mathrm{NO}_{2}$ is exposed to the ultraviolet radiation in the sunlight. Organic gas concentrations in the atmosphere have a significant effect on ozone levels. The large majority of this air pollution arises from combustion of fossil fuels (e.g., mobile sources of air pollution). It is reasonable to assume that lower respiratory tract presentations would be the highest during peak combustion of fossil fuels and that interventions to reduce fossil fuel combustion may have direct influence on health care resource use. The ground level ozone, is a secondary pollutant and can actually be scavenged from the air by fresh combustion pollutants.

The results presented here support the hypothesis that ED visits due to lower respiratory tract conditions are correlated with the ambient ground level ozone.

\section{ACKNOWLEDGMENT}

The authors appreciate the efforts of AHS-Edmonton Zone, especially Virginia Willis and Chris Huston, for securing these data. The authors acknowledge Environment Canada for providing the air pollution data from the National Air Pollution Surveillance (NAPS) network that was used in the study. The authors thank Dr. Mieczysław Szyszkowicz for helpful discussion, suggestions, and advice concerning the applied methodology. 


\section{REFERENCES}

1. Burnett RT, Smith-Doiron M, Stieb D, Raizenne M, Brook J, Dales RE, et al. The association between ozone and hospitalization for acute respiratory diseases in children under the age of two years. Am J Epidemiol. 2001;153:444-52, http:// dx.doi.org/10.1093/aje/153.5.444.

2. Choi M, Curriero FC, Johantgen M, Mills ME, Sattler B, Lipscomb J. Association between ozone and emergency department visits: An ecological study. Int J Environ Health Res. 2011;21(3):201-21, http://dx.doi.org/10.1080/09603123.2 010.533366 .

3. Larrieu S, Lefranc A, Gault G, Chatignoux E, Couvy F, Jouves B, et al. Are the short-term effects of air pollution restricted to cardiorespiratory diseases? Am J Epidemiol. 2009;169(10):1201-08, http://dx.doi.org/10.1093/aje/kwp032.

4. Peel JL, Tolbert PE, Klein M, Metzger KB, Flanders WD, Todd K, et al. Ambient air pollution and respiratory emergency department visits. Epidemiology. 2005;16(2):164-74, http://dx.doi.org/10.1097/01.ede.0000152905.42113.db.

5. Zemek R, Szyszkowicz M, Rowe BH. 2010. Air pollution and emergency department visits for otitis media: A casecrossover study in Edmonton, Canada. Environ Health Perspect. 2010;118:1631-6, http://dx.doi.org/10.1289/ehp. 0901675.

6. Szyszkowicz M, Porada E, Searles G, Rowe BH. Ambient ozone and emergency department visits for skin conditions. Air Qual Atmos Health. 2012;5(3):303-9, http://dx.doi/ org/10.1007/s11869-010-0092-5.

7. Szyszkowicz M, Porada E, Kaplan GG, Rowe BH. Ambient ozone and emergency department visits for cellulitis. Int J Environ Res Public Health. 2010;7(11):4078-88, http:// dx.doi.org/10.3390/ijerph7114078.

8. Szyszkowicz M, Porada E, Kaplan GG, Grafstein E. Ambient ozone as a risk factor for ED visits for cellulitis. Environ Pollut. 2012;1(2):105-11, http://dx.doi/org/10.5539/ep.v1n2p105.

9. Maclure M. The case-crossover design: A method for studying transient effects on the risk of acute events. Am J Epidemiol. 1991;133(2):144-53.
10. Environment Canada's weather archive [cited 2013 Oct 28]. Available from: http://climate.weatheroffice.gc.ca/.

11. Environment Canada [cited 2013 Oct 28]. Available from: http://www.etc-cte.ec.gc.ca/NapsData.

12. Janes H, Sheppard L, Lumley T. Case-crossover analyses of air pollution exposure data. Referent selection strategies and their implications for bias. Epidemiology. 2005;16(6):717-26, http://dx.doi.org/10.1097/01.ede.0000181315.18836.9d.

13. Chan-Yeung M, Aït-Khaled N, White N, Ip MS, Tan WC. The burden and impact of COPD in Asia and Africa. Int J Tuberc Lung Dis. 2004;8(1):2-14.

14. Mannino DM, Kiri VA. Changing the burden of COPD mortality. Int J Chron Obstruct Pulmon Dis. 2006;1(3):219-33, http://dx.doi.org/10.2147/copd.2006.1.3.219.

15. Carey SA, Ballinger CA, Plopper CG, McDonald RJ, Bartolucci AA, Postlethwait EM, et al. Persistent rhinitis and epithelial remodeling induced by cyclic ozone exposure in the nasal airways of infant monkeys. Am J Physiol Lung Cell Mol Physiol. 2011;300(2):242-54, http://dx.doi.org/10.1152/ ajplung.00177.2010.

16. Tonelli LH, Postolache TT. Airborne inflammatory factors: "from the nose to the brain". Front Biosci. 2010;2:135-52, http://dx.doi.org/10.2741/s52.

17. Villeneuve PJ, Chen L, Rowe BH, Coates F. Outdoor air pollution and emergency department visits for asthma among children and adults: A case-crossover study in northern Alberta, Canada. Environ Health. 2007;6:40, http://dx.doi. org/10.1186/1476-069X-6-40.

18. Stieb DM, Szyszkowicz M, Rowe BH, Leech JA. A Multi-city time-series analysis of air pollution and emergency department visits for cardiac and respiratory conditions. Environ Health. 2009;8:25, http://dx.doi.org/10.1186/1476-069X-8-25.

19. Fusco D, Forastiere F, Michelozzi P, Spadea T, Ostro B, Arcà $\mathrm{M}$, et al. Air pollution and hospital admissions for respiratory conditions in Rome, Italy. Eur Respir J. 2000;17(6): 1143-50, http://dx.doi.org/10.1183/09031936.01.00005501.

20. Szyszkowicz M. Ambient air pollution and daily emergency department visits for asthma in Edmonton, Canada. 
Int J Occup Med Environ Health. 2008;21:25-30, http:// dx.doi.org/10.2478/v10001-008-0002-3.

21. Szyszkowicz M, Thomson E, Rowe BH. Association of ambient air pollution with emergency department visits for health outcomes [abstract]. EUROEPI; 2013 Aug 11-14; Arhus, Denmark. Eur J Epi. 2013;(Suppl)28:Poster-242; p. S162. Forthcoming.

22. Szyszkowicz M. Remarks on ambient air pollution and health outcomes. ISRN Public Health. 2013;2013:1-5. Article ID 846297, http://dx.doi.org/10.1155/2013/846297.
23. Szyszkowicz M, Kauri LM, Malik S, Rowe BH. Ozone and emergency department visits for upper respiratory diseases. In: Sethi R, Manchanda S, Sethi V, editors. Ozone and ozone depletion: sources, environmental impact and health. New York: NOVA; 2013. p. 219-36.

This work is available in Open Access model and licensed under a Creative Commons Attribution-NonCommercial 3.0 Poland License - http://creativecommons.org/ licenses/by-nc/3.0/pl/deed.en. 